\title{
Kinetics of crystallization of a Fe-based multicomponent amorphous alloy
}

\author{
ARUN PRATAP*, T LILLY SHANKER RAO ${ }^{\dagger}$, KINNARY PATEL and \\ MUKESH CHAWDA ${ }^{\dagger \dagger}$ \\ Applied Physics Department, Faculty of Technology and Engineering, The M.S. University of Baroda, \\ Vadodara 390001 , India \\ ${ }^{\dagger}$ Electronics Department, Narmada College of Science and Commerce, Zadeshwar, Bharuch 392 011, India \\ ${ }^{\dagger \dagger}$ Physics Department, Polytechnic, M.S. University of Baroda, Vadodara 390 002, India
}

MS received 3 September 2009

\begin{abstract}
The Fe-based multicomponent amorphous alloys (also referred to as metallic glasses) are known to exhibit soft magnetic properties and, it makes them important for many technological applications. However, metallic glasses are in a thermodynamically metastable state and in case of high temperature operating conditions, the thermally activated crystallization would be detrimental to their magnetic properties. The study of crystallization kinetics of metallic glasses gives useful insight about its thermal stability. In the present work, crystallization study of $\mathrm{Fe}_{67} \mathrm{Co}_{18} \mathrm{~B}_{14} \mathrm{Si}_{1}(2605 \mathrm{CO})$ metallic glass has been carried out using differential scanning calorimetry (DSC) technique. Mössbauer study has also been undertaken to know the phases formed during the crystallization process. The alloy shows two-stage crystallization. The activation energy has been derived using the Kissinger method. It is found to be equal to $220 \mathrm{~kJ} / \mathrm{mol}$ and $349 \mathrm{~kJ} / \mathrm{mol}$ for the first and second crystallization peaks, respectively. The Mössbauer study indicates the formation of $\alpha$-(Fe, Co) and $(\mathrm{Fe}, \mathrm{Co})_{3} \mathrm{~B}$ phases in the alloy.
\end{abstract}

Keywords. Fe-based metallic glass; crystallization kinetics; Mössbauer study.

\section{Introduction}

Metallic glasses of magnetic nature produced by rapid quenching of melt of iron based transition-metal-metalloid systems, have been of scientific and technological interest in the recent past (Cantor 1978). Even though these metallic glasses lack long-range crystalline order, they show ferromagnetic properties (Gubnov 1960). They represent a metastable state and tend to show structural relaxation with time which gets accelerated at higher temperature. At high enough temperatures, they crystallize irreversibly in a more stable state. Fundamental interest in multicomponent alloys has been revived due to nano-structure formation in these amorphous alloys, which consequently led to better magnetic performance (Yoshizawa 1988).

The kinetics of crystallization plays an important role in physics, chemistry, ceramic and metallurgical sciences. Thermal analysis methods, including DSC, are extensively used for studying kinetics of chemical reactions (Piloyan et al 1966; Tanabe and Otsuka 1977) and crystallization of glasses (Matusita and Sakka 1979; Dos Santos and Dos Santos 2001; Pratap et al 2001) since they are easy to be carried out and are quite sensitive

\footnotetext{
*Author for correspondence (apratapmsu@yahoo.com)
}

(Kelton 1993). The determination of basic data on crystallization kinetics is important in establishing the mechanism of crystal nucleation and growth.

In the present paper, we report the study of crystallization behaviour using DSC and Mössbauer spectroscopy in the metallic glass $2605 \mathrm{CO}$. The DSC is utilized to determine the activation energy of crystallization and associated frequency factor of the sample. The Mössbauer spectroscopy is an excellent tool (Greneche 1998) to investigate metallic glasses because it can select resonating nuclei of particular species, and probe the nature of their immediate surroundings (Gonser and Preston 1983). Besides, annealing treatments (occasionally in an external field under controlled atmosphere) may be applied to asquenched metallic glasses to improve their soft magnetic properties. Annealing stabilizes the magnetic properties, reduces the thermal stresses, removes local homogeneities and controls magnetic anisotropies. Therefore, the efficiency of thermal treatments can be easily checked (Greneche 1998) by Mössbauer experiments.

\section{Experimental}

Specimens of amorphous $\mathrm{Fe}_{67} \mathrm{Co}_{18} \mathrm{~B}_{14} \mathrm{Si}_{1}$ (2605CO) ribbons, prepared by single roller melt spinning technique 
were procured from Allied Corporation, USA. The amorphous nature of ribbons was confirmed by X-ray diffraction (XRD) and transmission electron microscopy (TEM). The as-quenched samples of $\mathrm{Fe}_{67} \mathrm{Co}_{18} \mathrm{~B}_{14} \mathrm{Si}_{1}$ ribbons were heated in DSC (DSC-50, Shimadzu, Japan) at four linear heating rates $(4,810$ and $16 \mathrm{deg} / \mathrm{min})$ from room temperature to $720 \mathrm{~K}$ in air. The DSC scans were recorded by a thermal analyzer (TA-50 WSI, Shimadzu, Japan) interfaced to a computer. The detection sensitivity of the instrument is $\sim 10 \mu \mathrm{W}$.

The as-received samples of $2605 \mathrm{CO}$ were evacuated in quartz ampoules to $10^{-3}$ torr and then sealed under vacuum and annealed at $400^{\circ} \mathrm{C}$ and $500^{\circ} \mathrm{C}$ for about $3 \mathrm{~h}$. Mössbauer spectra of all the samples (as-received, annealed at $400^{\circ} \mathrm{C}$ and $500^{\circ} \mathrm{C}$ ) were recorded using a constant acceleration spectrometer, whose line width is $0 \cdot 28 \mathrm{~mm} / \mathrm{s}$. The source used was $\mathrm{Co}^{57}$ in an Rh matrix.

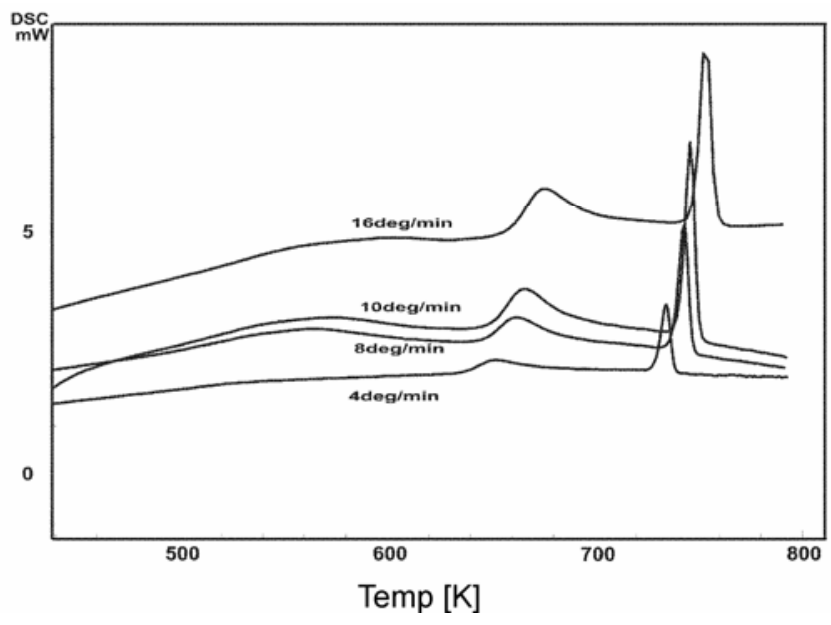

Figure 1. DSC thermograms of $2605 \mathrm{CO}$ at different heating rates.

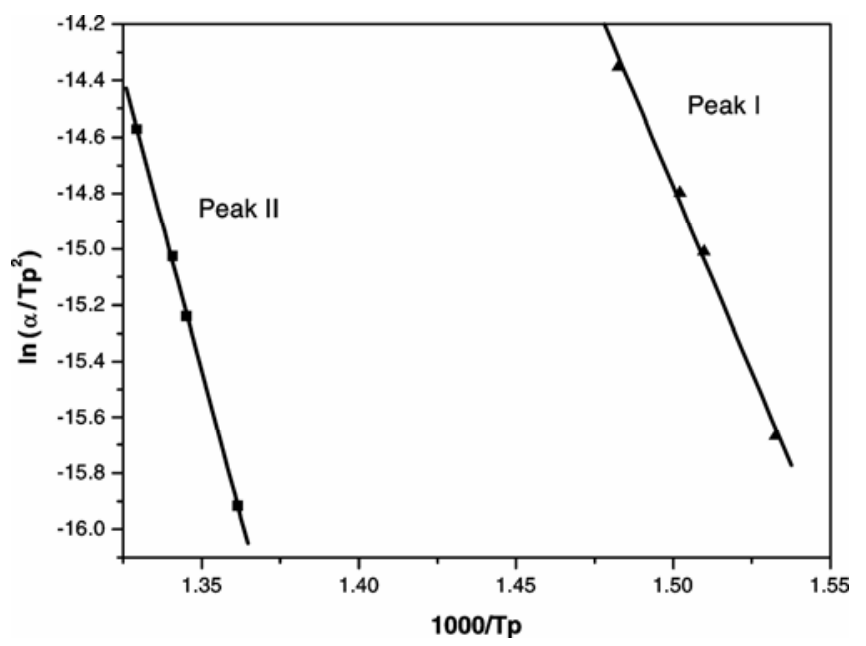

Figure 2. Kissinger plot, $\ln \left(\alpha / T_{\mathrm{p}}^{2}\right)$ vs $1000 / T_{\mathrm{p}}$ for first and second peaks.

\section{Results and discussion}

\subsection{Determination of activation energy using Kissinger method}

The DSC curves of as-quenched samples at four heating rates give two-stage crystallization events as shown in figure 1 . The activation energy for crystallization of an amorphous alloy under a linear heating rate can be estimated using Kissinger's peak shift method (Kissinger 1957), which relates the peak temperature, $T_{\mathrm{p}}$, with heating rate $(\alpha)$ through the equation

$$
\ln \left(\frac{\alpha}{T_{\mathrm{p}}^{2}}\right)=-\frac{E_{\mathrm{c}}}{R T_{\mathrm{p}}}+\ln \left(\frac{A R}{E_{\mathrm{c}}}\right),
$$

Table 1. Values of activation energy and the frequency factor for the two crystallization peaks.

\begin{tabular}{lcc}
\hline Crystallization peak & $E_{\mathrm{c}}(\mathrm{kJ} / \mathrm{mol})$ & $A\left(\mathrm{~s}^{-1}\right)$ \\
\hline First & 220 & $1.75 \times 10^{15}$ \\
Second & 349 & $3.4 \times 10^{22}$ \\
\hline
\end{tabular}

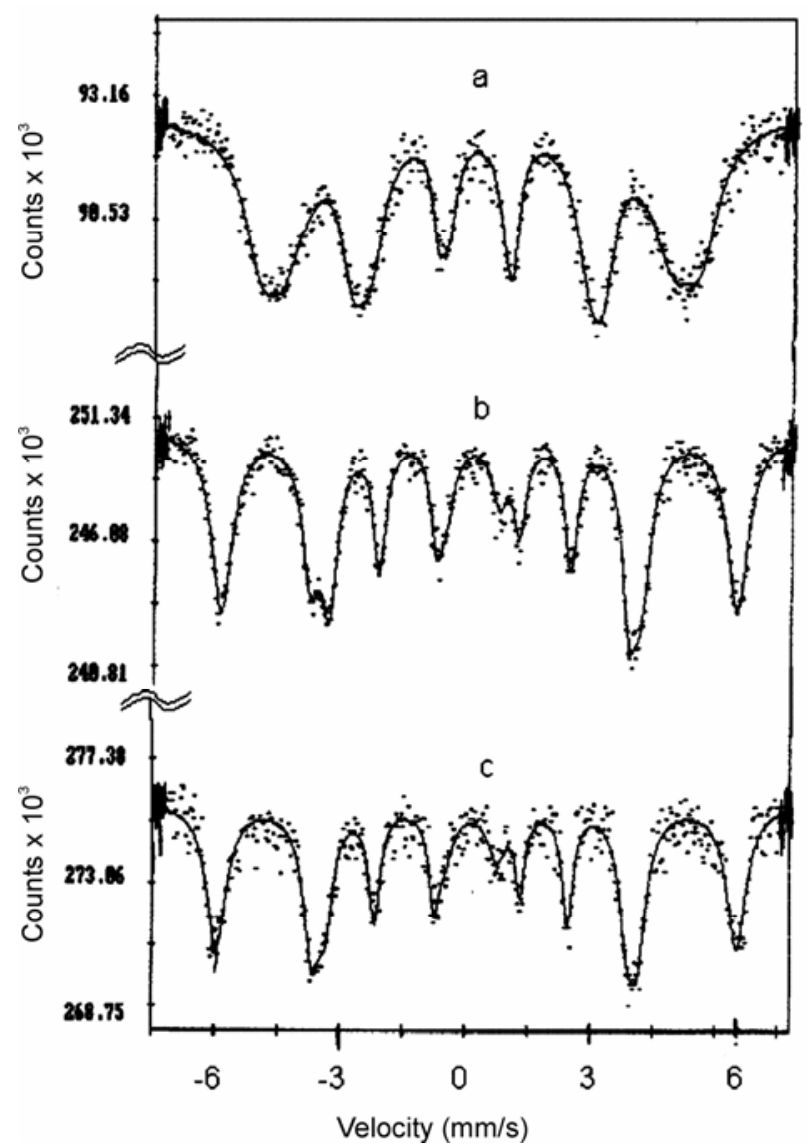

Figure 3. Mössbauer spectra: (a) as-received sample, (b) a sample annealed at $400^{\circ} \mathrm{C}$ for $3 \mathrm{~h}$ and (c) a sample annealed at $500^{\circ} \mathrm{C}$ for $3 \mathrm{~h}$. 
where $E_{\mathrm{c}}$ is the activation energy for crystallization, $T_{\mathrm{p}}$ the peak temperature and $A$ the frequency factor. Figure 2 shows the graph of $\ln \left(\alpha / T_{\mathrm{p}}^{2}\right)$ vs $1000 / T_{\mathrm{p}}$ which is a straight line with a slope $\left(-E_{\mathrm{c}} / R\right)$ and an intercept of $\ln$ $\left(A R / E_{\mathrm{c}}\right)$. The activation energy and the frequency factor for the first and second crystallization peaks are given in table 1. These activation energy values obtained for first and second events are close to the values reported for a sample of the same multicomponent alloy with a slightly different composition $\left(\mathrm{Fe}_{65} \mathrm{Co}_{18} \mathrm{~B}_{16} \mathrm{Si}_{1}\right)$, being 260 and $394.9 \mathrm{~kJ} / \mathrm{mol}$, respectively (Baro et al 1991).

\subsection{Mössbauer study}

In case of as received samples, the least square fitted spectra showed (figure 3(a)) three magnetic sextets with hyperfine magnetic fields (HMF) of $300 \mathrm{KOe}, 270 \mathrm{KOe}$ and $230 \mathrm{KOe}$. These three sites correspond to $(\mathrm{Fe}, \mathrm{Co})_{3} \beta$ phase formation into the matrix. However, on annealing the samples to $400^{\circ} \mathrm{C}$ for $3 \mathrm{~h}$ only two magnetic sites with sextets of $360 \mathrm{KOe}$ and $230 \mathrm{KOe}$ were observed (figure $3(\mathrm{~b})$ ). The site with $360 \mathrm{KOe}$ here shows that there is $\alpha$-(Fe-Co) phase formation. The site population of this phase was found to be $41.8 \%$ with respect to $58.2 \%$ of $(\mathrm{Fe}, \mathrm{Co})_{3} \beta$ phase. On further annealing to $500^{\circ} \mathrm{C}$ for $3 \mathrm{~h}$ there was no change in fields $(360 \mathrm{KOe}$ and $230 \mathrm{KOe})$, but the population of $\alpha-(\mathrm{Fe}, \mathrm{Co})$ phase increased to $58.2 \%$ at the cost of $(\mathrm{Fe}, \mathrm{Co})_{3} \beta(41.8 \%)$ phase (figure $3(c))$.

XRD studies (Baro et al 1991) of crystallized samples of slightly different composition i.e. $\mathrm{Fe}_{65} \mathrm{Co}_{18} \mathrm{~B}_{16} \mathrm{Si}_{1}$, too exhibits main peaks corresponding to $\alpha$-(Fe, Co). However, in their XRD results, the final products of crystallization are $b c c \alpha-(\mathrm{Fe}, \mathrm{Co})$ and orthorhombic $(\mathrm{Fe}, \mathrm{Co})_{3} \mathrm{~B}$.

\section{Conclusions}

The Fe-based multicomponent amorphous alloy $\left(\mathrm{Fe}_{67} \mathrm{Co}_{18}\right.$ $\mathrm{B}_{14} \mathrm{Si}_{1}$ ) exhibits two-stage crystallization. The activation energy values evaluated for the two stages are consistent with the reported data for a similar alloy with slightly different composition $\left(\mathrm{Fe}_{65} \mathrm{Co}_{18} \mathrm{~B}_{16} \mathrm{Si}_{1}\right)$. The Mössbauer study of the as-received sample and the specimens annealed at $400^{\circ} \mathrm{C}$ and $500^{\circ} \mathrm{C}$, on analysis, provide the precipitating phases $(\alpha-(\mathrm{Fe}-\mathrm{Co}))$ and $\left((\mathrm{Fe}-\mathrm{Co})_{3} \beta\right)$. Similar phase precipitations have been reported (Bhatnagar et al 1985) in earlier crystallization studies of the present system.

\section{References}

Baro M D, Surinach S, Diego J A and Clavaguera-Mora M T 1991 Mater. Sci. \& Eng. A133 807

Bhatnagar A K, Ganeshan D, Bhanu Prasad B, Parasher R S and Jagannathan R 1985 in Rapidly quenched metals $V$ (eds) S Steeb and H Warlimont (Netherlands: Elsevier) p. 295

Cantor B (ed.) 1978 Rapidly quenched metals III (London: The Metals Society) $\mathbf{1} \mathbf{2}$

Dos Santos D R and Dos Santos D S 2001 Mater. Res. 447

Gonser U and Preston R 1983 Topics in applied physics: Glassy metals II (New York: Springer) p. 93

Greneche J M 1998 Hyperfine Interactions 111261

Gubnov A I 1960 Fiz. Tvred. Tela (Leningrad) 2502

Kelton K F 1993 J. Non-Cryst. Solids 163283

Kissinger H E 1957 Anal. Chem. 291702

Matusita and Sakka S 1979 Phys. Chem. Glasses 2081

Piloyan G O, Ryabchikov I D and Novikova O S 1966 Nature 2121229

Pratap A, Raval K G and Awasthi A M 2001 Mater. Sci. \& Eng. A304-306 357

Tanabe S and Otsuka R 1977 Netsu 4139

Yoshizawa Y, Oguma S and Yamauchi K 1988 J. Appl. Phys. 646094 